\title{
Precision enology in Tawny Port wine aging process: Monitoring barrel to barrel variation in oxygen, temperature and redox potential
}

\author{
F. Cosme ${ }^{1, \text { a }}$, R. Morais ${ }^{2}$, E. Peres ${ }^{2}$, J.B. Cunha ${ }^{2}$, I. Fraga ${ }^{3}$, J. Milheiro ${ }^{1}$, L. Filipe-Ribeiro ${ }^{1}$, J. Mendes ${ }^{2}$, and F.M. Nunes ${ }^{1}$ \\ ${ }^{1}$ Chemistry Research Centre - Vila Real (CQ-VR), Food and Wine Chemistry Lab, University of Trás-os-Montes and Alto Douro, \\ 5000-801 Vila Real, Portugal \\ 2 INESC TEC - Campus da FEUP, Porto, Portugal and UTAD - University of Trás-os-Montes and Alto Douro, 5000-801 Vila Real, \\ Portugal \\ ${ }^{3}$ Centre for the Research and Technology of Agro-Environment and Biological Sciences (CITAB), University of Trás-os-Montes and \\ Alto Douro, 5000-801 Vila Real, Portugal
}

\begin{abstract}
Tawny Port wine is a category of the famous Portuguese fortified wine commercialized worldwide and produced in the Douro Demarcated Region. Tawny Port wine oxidative aging is a multifactorial process critical for reaching the wanted quality. Real time monitoring of important intrinsic and extrinsic factors that are known to affect both time and quality of the aging process are important to optimize and to manage the natural variability between wines aged in different long-used wood barrels. This study presents the design, development and implementation of a remote distributed system to monitor parameters that are known to be critical for Tawny Port wine aging process. Results indicate that the distributed monitoring system was capable to detect differences between oak wood barrels and between the different storage conditions. Indeed, oxygen and redox potential were the wine's parameters where the differences found between different barrels were greater under the same storage conditions. Considering that Tawny Port wine aging process is oxidative, a variation in the wine's aging process between different wood barrels is to be expected. Actually, significant differences were detected in the oxygen consumption rate amongst the different barrels. Differences in the phenolic composition was also observed in the aged wine (controlled temperature and room temperature).
\end{abstract}

\section{Introduction}

Tawny Port wine is produced only from the authorized grape varieties grown and vinified in the Douro Demarcated Region in Northern Portugal, being the principal red grape varieties recommended "Touriga Nacional", "Mourisco Tinto", "Bastardo", "Tinta Roriz", "Tinta Cão", "Tinta Amarela", "Tinta Barroca", "Touriga Franca", and "Tinta Francisca", since these grape varieties produce wines with a stable color, fruity aromas, and sugar content characteristics required to produce good quality Port wines [1]. The Port wine vinification process is characterized by stopping the fermentation process with wine spirt $(77 \% \mathrm{v} / \mathrm{v})$ at the desired sugar levels (sweet, medium-sweet, dry). The final alcohol content in Port wine ranged between 19 and $22 \%(\mathrm{v} / \mathrm{v})$. Aging is an important feature for Tawny Port wines. Therefore, after fortification with wine spirit, it is aged in used wood barrels, from three years to many decades, exposing them to gradual oxidation and evaporation, and blended in such a way that the final wine is a blend of wines with different ages. Therefore, the complexity and the quality of the final wines are dependent on numerous variables associated to the wine characteristics and others to external factors. Since high quality grapes, although essential, do

a e-mail: fcosme@utad.pt not guarantee high quality wines, the oxidative wine aging process is the most important and critical operation in the Tawny Port wine production. It is empirically known that external factors, such as wine dissolved oxygen, storage temperature and oxygen exposure have a significant influence in the wine aging process. Additionally, wood barrels' utilization time and wood type used for their construction are also variables to account for. Wine $\mathrm{pH}$, as well as the phenolic oxidation, are also main factors for a successful wine aging process [2-6]. In Port wines, two types of polymerization reactions seems to occur at the same time. The extent of each reaction appears to depend on the concentration of acetaldehyde present in the wine. Therefore, polymeric pigments are formed from anthocyanins by condensation reactions with flavanols directly $[7,8]$ or mediated by acetaldehyde [9]. The color evolution observed during the wine aging process is essentially due to anthocyanin reaction mediated by acetaldehyde and pyruvic acid: acetaldehyde is formed from ethanol by a coupled auto-oxidation of orthodiphenolic compounds, resulting in $\mathrm{H}_{2} \mathrm{O}_{2}$ formation that oxidizes ethanol to acetaldehyde. Port wine color increases up to $80 \%$ during the first months of maturation, depending on the concentration of free acetaldehyde present in the young Port wine [9]. This initial increase in color during Port wines aging is attributed to interactions of free aldehyde with anthocyanins resulting in the formation of 
acetaldehyde-containing oligomeric pigments that are more colored at Port wine $\mathrm{pH}$ than the free anthocyanins from which they are derived. An increase in acetaldehyde levels increases the proportion of anthocyanin-tannin polymerization [10-14]. Therefore, the time needed to reach the Tawny Port wine profile concerning the sensory and chromatic characteristics, depends on all the aforementioned factors, which means that it is necessary to control the wine aging process. This is done with extremely subjective parameters, principally based on sensory analysis. Such natural unchecked variability demands for process management and control, resulting in high costs. Since, each of the wines aging process stages must be carefully monitored, this is usually done by manual sampling controlling chemical and sensory parameters, which makes the manual monitoring operations time consuming to winery team. Increasing the predictability of a wine's aging potential as well as of the final product's quality and consistency, can contribute decisively to improve stock management and to reduce costs. The establishment of a relation between parameters that affect the wine aging process such as temperature, dissolved oxygen levels, $\mathrm{pH}$ and redox potential, the final wine quality and the time for reaching them, could represent both an economic and quality addedvalue for the Port wine sector. Therefore, to optimize the production and quality management of the Tawny Port wine, "Precision Enology (PE)" is required. The monitoring of the Tawny Port wine aging processes through technological solutions that make available realtime data of wine and environmental parameters are important to the development of decision-support tools for PE. This study presents the design, development and implementation of a remote distributed system to monitor parameters recognized to influence the Tawny Port wine aging process. A set of $250 \mathrm{~L}$ long-used wood barrels were instrumented in two adjacent wineries - one of them with temperature control - in the Douro Demarcated Region. Sensors located in the wineries and in each wood barrel are connected to communication networks that collect data for local and remote storage. A remote management platform - mySense [15] - is responsible for receiving sensors' data every 15 minutes and perform as a decision support system for the Tawny Port wine aging process management. The purpose of this work was to study the behavior of Tawny Port wine aging in long-used wood barrels to understand the development of wine $\mathrm{pH}$, dissolved oxygen, redox potential and phenolic compounds at winery scale conditions and their impact on the Tawny Port wine aging process, as well as their dependence on the wine's storage temperatures.

\section{Material and methods}

\subsection{Monitoring system's architecture}

The monitoring of the Tawny Port wine aging process is performed in two equal wineries - one of them with temperature control - in Vallegre, Porto S.A Wines farm, located in Pinhão, Portugal (N41 $\left.{ }^{\circ} 10^{\prime} 30.7^{\prime \prime} E 7^{\circ} 33^{\prime} 39.9^{\prime \prime} 95\right)$. The wine was put in the wood barrels in February 2016. Eight long-used oak wood barrels were organized in each of the two wineries. Each barrel was instrumented with sensors to measure important parameters in the wine's aging process, namely: $\mathrm{pH}$, redox potential, dissolved oxygen and temperature. Additionally, two of the environmental parameters of both wineries - temperature and relative humidity - are also monitored. The monitoring process was carried out using a RS-485 industrial network, which interconnects sensors that continuously measure wine temperature, $\mathrm{pH}$, redox potential and wine's dissolved oxygen, as well as other sensors that measure parameters linked to the barrels' environmental context, such as room temperature and relative humidity [16].

\subsubsection{Sensors and interconnections}

The monitoring of wine parameters that were considered important to its aging process is performed using two specific sensors. While $\mathrm{pH}$, redox potential $(\mathrm{mV})$ and temperature values are measured using PHEHT sensors (SN-PPHRB, Ponsel, France), dissolved oxygen (\%, mg/L or ppm) is monitored with an optical technology sensor: OPTOD®(SN-PODOA, Ponsel, France). Furthermore, both sensors have an IP68 level of protection, communicate through a RS-485 bus and are appropriate for being in permanent contact with wine.

For the environmental monitoring of both wineries, the sensors in use are the HMT310 (Vaisala, Sweden), that allow the measurement of numerous parameters, such as: temperature $\left({ }^{\circ} \mathrm{C}\right)$, relative humidity $(\% \mathrm{RH})$, absolute humidity $\left(\mathrm{g} / \mathrm{m}^{3}\right)$, dew point $\left({ }^{\circ} \mathrm{C}\right)$, frost point $\left({ }^{\circ} \mathrm{C}\right)$, wet bulb temperature $\left({ }^{\circ} \mathrm{C}\right)$, water vapor pressure $(\mathrm{hPa})$, enthalpy $(\mathrm{kJ} / \mathrm{kg})$, mixing ratio $(\mathrm{g} / \mathrm{kg})$, and humid air volume/dry air volume (ppm).

\subsubsection{Hub and local data management}

The concentrator or hub is the monitoring system's element responsible for managing communications in both the RS-485 and RS-232C networks. Furthermore, it guarantees network connectivity with any given wireless sensors that may be added to the monitoring system and with the farm's wired Internet service to relay data remotely. The platforms chosen single-board computer (SBC) - a Raspberry Pi - is presently one of the most versatile and popular, mainly due to its low-cost and to its software: both the operation system (OS) and most of the associated software solutions are or are based on open-source. The hub operation is managed by a Java application, whose key functionalities are (i) to acquire data from the monitoring system's sensors, (ii) to provide a local temporary data storage and (iii) to transmit the attained data to the remote platform.

\subsection{Sensors responses corrections}

As the reference electrode used for redox potential was a silver/silver chloride electrode, the measured potential was corrected to a standard hydrogen electrode. To calculate corrected redox potential for $\mathrm{pH}$ in more complex biological matrices, the Nernst $\mathrm{pH}$ correlation factor $(\mathrm{mV} / \mathrm{pH}$ unit) must be experimentally determined, as its value may differ according to the nature of the redox molecules in the medium. To determine the Nernst $\mathrm{pH}$ correlation factor for redox potential correction, the study's initial wine and a Tawny Port wine were used to establish the $\mathrm{pH}$ - redox potential correlation for the proposed monitoring system. The $\mathrm{pH}$ value was adjusted by addition 
of $\mathrm{HCl} 1 \mathrm{M}$ for lowering it and $\mathrm{NaOH} 1 \mathrm{M}$ for increasing it by approximately $0.5 \mathrm{pH}$ units, in relation to the wines' natural $\mathrm{pH}$. The adjust solutions were then cooled down to approximately $5^{\circ} \mathrm{C}$ and heated up to $35^{\circ} \mathrm{C}$, while the $\mathrm{pH}$ and redox potential parameters were measured, along with the room's temperature $\left(20^{\circ} \mathrm{C}\right)$. Subsequently, the measured redox potentials were corrected to redox potential by using the reference electrode potential corrected for $25^{\circ} \mathrm{C}$. The only factor - amongst temperature and $\mathrm{pH}-$ in these conditions that had a significant effect $(p<0.001)$ on the redox potential measure was $\mathrm{pH}$. However, no significant differences were observed between the values obtained for the initial wine $(49.23 \pm$ 9.64) and for the Tawny Port wine $(56.83 \pm 10.78)$. Therefore, the parameter was calculated by pooling the $\mathrm{pH}$ and redox potential values from both wines, obtaining a correction factor of $53.17 \pm 7.68$. The used $\mathrm{pH}$ sensors have an automatic temperature compensation for $25^{\circ} \mathrm{C}$ and therefore the acquired $\mathrm{pH}$ values were not corrected.

\subsection{Cumulative wine exposure to daily temperature, oxygen, $\mathrm{pH}$ and redox potential}

To assess the complete wines' exposure to oxygen, temperature, $\mathrm{pH}$ and redox potential during the aging process, the cumulative daily exposures were calculated.

\subsection{Color intensity, hue and total anthocyanins}

Color intensity and hue were determined according to OIV [17]. Total anthocyanins were determined according to Ribéreau-Gayon et al. [18]. Analyses were performed in duplicate.

\subsection{Quantification of non-flavonoids, flavonoids and total phenols}

Non-flavonoid phenolics were quantified according to Kramling and Singleton [19], and total phenolic content according to Ribéreau-Gayon et al. [18]. Analyses were performed in duplicate.

\section{Results and discussion}

To know the influence of storage temperature on the Tawny Port wine aging process, the same fortified wine was kept in two arrangements of long-used wood barrels $(250 \mathrm{~L})$ in neighboring wineries: one at room temperature and other with controlled temperature at $\sim 27^{\circ} \mathrm{C}$. Throughout the first seven days of the aging process, both wineries were at room temperature. Then, temperature was elevated in the winery with controlled temperature.

\subsection{Oxygen consumption}

Data acquired shows that all barrels from both arrangements - kept at room temperature or at a controlled temperature - had two different and perfect oxygen consumption phases, with different kinetics. The first phase occurred about seven days for all barrels, the second phase happened after 35 additional days for the barrels stored at room temperature and after 24 additional days for the barrels kept at a controlled temperature. After both these phases, the dissolved oxygen levels stayed low in all barrels $(<0.1 \mathrm{mg} / \mathrm{L})$. Nevares et al. [20] also observed two diverse oxygen consumption phases for oxygen saturated white and red wines. The dissolved oxygen levels decrease observed after filling up the barrels is possibly linked to phenolic compounds oxidation in the presence of iron, copper and sulfur dioxide in the wine [21]. Apparent kinetic constants were significantly different for all barrels $(p<0.001)$, in both oxygen consumption phases, at room or controlled temperature conditions, allowing to conclude different rates of the same phenomena or different phenomena happening in the diverse barrels. The difference between oxygen consumption rate constants was higher at lower temperatures, when compared to the barrels kept at a controlled higher temperature. After $50,000 \mathrm{~min}$, oxygen levels are higher in the barrels kept in winery at room temperature $\left(3.3 \pm 0.3 \mathrm{mgO}_{2} / \mathrm{L} / \mathrm{month}\right.$ compared with $1.9 \pm 0.8 \mathrm{mgO}_{2} / \mathrm{L} /$ month, $p<0.0178$ ). This can be explained by oxygen's lower solubility in wine at higher temperatures [22] or by the higher velocity of oxygen consumption at higher temperatures.

\subsection{Redox potential}

As well dissolved oxygen content in wine, redox potential was likewise measured using a platinum electrode. Wine's $\mathrm{pH}$ affects the measured redox potential values and consequently the potential values were corrected to a constant $\mathrm{pH}$ value of 3.5. Simultaneous monitoring of the redox potential and dissolved oxygen levels permitted to get an interesting understandings on the redox potential evolution with the dissolved oxygen quantity present in Tawny Port wine. In the first oxygen consumption phase, the redox potential remained practically constant. Indeed, an exponential positive correlation between oxygen and redox potential was only observed within the oxygen content range from $\sim 1.0 \mathrm{mg} / \mathrm{L}$ and $\sim 4660.25 \mathrm{mg} / \mathrm{L}$ for room temperature and $\sim 4670.05 \mathrm{mg} / \mathrm{L}$ for controlled temperature storage, for both wineries. The decrease in the Tawny Port wine redox potential coincides with the wine's second phase oxygen level decrease, showing that barrels' redox potential can also be used to detect wine's oxygen level variation, as described in Danilewicz [21].

\subsection{Aging temperature}

To compare the influence of the aging temperature on the evolution of the measured variables $(\mathrm{pH}$, oxygen and redox potential) in both wineries and without two equal barrels, the Tawny Port wine cumulative daily exposure to temperature, oxygen, $\mathrm{pH}$ and redox potential was calculated and averaged. The results showed that the Tawny Port wine's average cumulative daily exposure to temperature was significantly higher in the controlled temperature winery. Wine's average cumulative daily exposure to $\mathrm{pH}$, after aging 228 days, was not significantly different between both wineries. Therefore, storage temperature, in average, did not change wine's $\mathrm{pH}$ during the aging process, although some differences are observed between barrels. The change in the wine's cumulative daily oxygen exposure in both wineries was not significantly different, in average. Nevertheless, differences observed between each barrel in both wineries were of nearly $12 \%$, but those differences did not occurred at the same aging period in both wineries. 


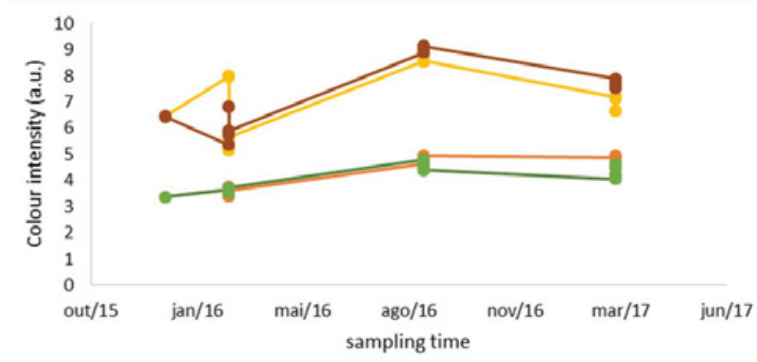

A
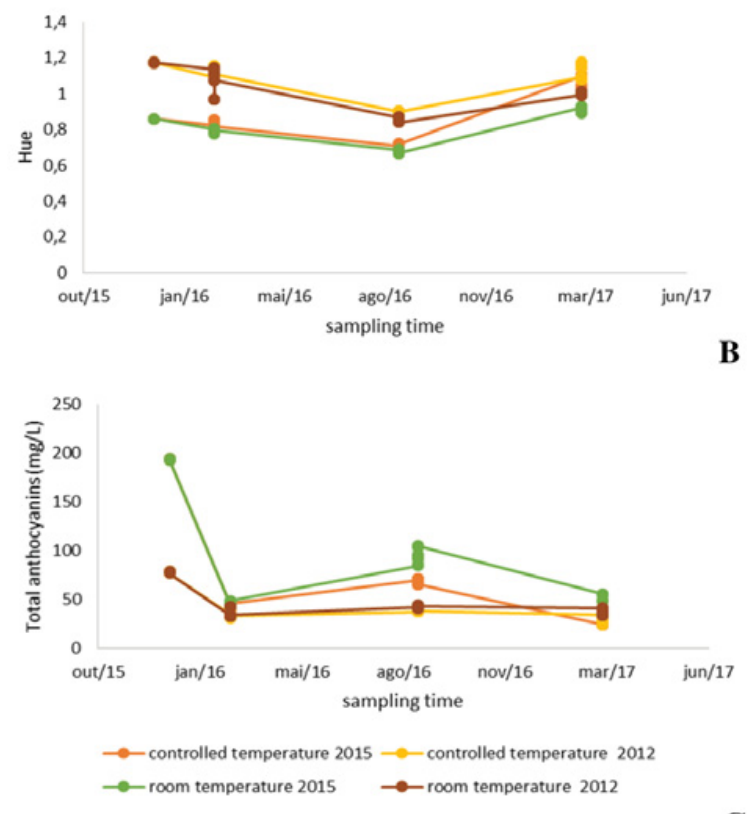

C

Figure 1. Color intensity (A), hue (B) and total anthocyanins (C) evolution during 15 month aging time of the two Tawny Port wine (vintage 2012 and vintage 2015) in a winery with controlled temperature and another at room temperature.

\subsection{Color intensity, hue and total anthocyanins}

Color intensity, hue and total anthocyanins are directly related to the wine color, and for this reason also with the acceptability of the final product by the consumer. As such, the correct evaluation and monitoring of these parameters during the wine aging process are very important. This parameter provides a chemical indication of the wine evolution during the aging process, and its evaluation is important for the wine aging process as well as to understand how to optimize this process. Figure 1 shows the color intensity evolution, hue and total anthocyanins of the two Tawny Port wines aged (vintage 2012 and vintage 2015) in a winery with controlled temperature and another at room temperature.

The color evolution observed during the Port wine aging process is essentially due to anthocyanin reaction mediated by acetaldehyde and pyruvic acid. In our work, an increase in the Tawny Port wine color intensity was observed from 3.36 to 4.68 u.a. and from 6.39 to 7.18 u.a in the Tawny Port wine aged the winery with controlled temperature (vintage 2015 and 2012, respectively). In the winery with room temperature color intensity increased from 3.36 to 4.23 u.a and from 6.39 to 7.61 u.a in the Tawny Port wine from vintage 2015 and 2012, respectively. This initial increase in color during Tawny Port wines aging is attributed to interactions of free aldehyde with anthocyanins resulting in the formation of acetaldehyde-containing oligomeric pigments that are more colored at Port wine $\mathrm{pH}$ than the free anthocyanins from which they are derived. An increase in acetaldehyde concentration increases the amount of anthocyanin-tannin polymerization [10-14].

The hue also increased from 0.863 to 1.047 and from 0.863 to 0.906 in the Tawny Port wine from vintage 2015 , in the winery with controlled temperature and in the winery with room temperature, respectively. The hue decreased from 1.169 to 1.083 and from 1.169 to 1.0117 in the Tawny Port wine from vintage 2012 aged in the winery with controlled temperature and in the winery at room temperature, respectively.

Total anthocyanins decreased in the Tawny Port wines aged under controlled temperature from $190 \mathrm{mg} / \mathrm{L}$ to $30 \mathrm{mg} / \mathrm{L}$ and from $70 \mathrm{mg} / \mathrm{L}$ to $30 \mathrm{mg} / \mathrm{L}$ in the wine from vintage 2015 and 2012, respectively. For the Tawny Port wines aged at room temperature the decrease observed was lesser namely from $190 \mathrm{mg} / \mathrm{L}$ to $50 \mathrm{mg} / \mathrm{L}$ and from $70 \mathrm{mg} / \mathrm{L}$ to $37 \mathrm{mg} / \mathrm{L}$, respectively for the wine from vintage 2015 and 2012.

\subsection{Quantification of non-flavonoids, flavonoids and total phenols}

In the wine industry the total phenolic compounds are used as an indicator of the content of phenolic compounds in wines. However, wine contains a very large diversity of phenolic compounds, which do not exhibit the same reactivity during the aging process. Thus, it is necessary to specify the different classes of phenolic compounds present in wine, namely, non-flavonoids, flavonoids and total phenolic compounds, to verify the implication of each of these classes in the polymerization process during wine aging. The evolution of the total phenolic compounds, flavonoids and non-flavonoid phenolic compounds during the Tawny Port wine aging process is presented in Fig. 2.

Total phenolic compounds decreased from $544 \mathrm{mg} / \mathrm{L}$ gallic acid to $512 \mathrm{mg} / \mathrm{L}$ gallic acid and from $995 \mathrm{mg} / \mathrm{L}$ of gallic acid to $707 \mathrm{mg} / \mathrm{L}$ of gallic acid in the Tawny Port wine aged in a winery with control temperature, respectively for the vintage 2015 and 2012. For the Tawny Port wine aged at room temperature the decrease observed was from $544 \mathrm{mg} / \mathrm{L}$ gallic acid to $501 \mathrm{mg} / \mathrm{L}$ gallic acid and from $995 \mathrm{mg} / \mathrm{L}$ gallic acid to $677 \mathrm{mg} / \mathrm{L}$ gallic acid for the wine from vintage 2015 and 2012, respectively.

The flavonoid phenolic compounds decreased from $477 \mathrm{mg} / \mathrm{L}$ gallic acid to $416 \mathrm{mg} / \mathrm{L}$ gallic acid and from $933 \mathrm{mg} / \mathrm{L}$ gallic acid to $610 \mathrm{mg} / \mathrm{L}$ gallic acid in the wine aged in the winery with controlled temperature, respectively for the wine from vintage 2015 and 2012. For the wine aged at room temperature, decreases observed for flavonoid compounds were from $477 \mathrm{mg} / \mathrm{L}$ of gallic acid to $413 \mathrm{mg} / \mathrm{l}$ of gallic acid for the wine from vintage 2015 and 2012, respectively.

The non-flavonoid phenolic compounds increased during the aging process, from $67 \mathrm{mg} / \mathrm{L}$ of gallic acid to $96 \mathrm{mg} / \mathrm{L}$ of gallic acid and from $62 \mathrm{mg} / \mathrm{L}$ gallic acid to $96 \mathrm{mg} / \mathrm{L}$ of gallic acid, respectively for the wine from vintage 2015 and for the wine from vintage 2012. The wines aged at room temperature increased from $67 \mathrm{mg} / \mathrm{L}$ 


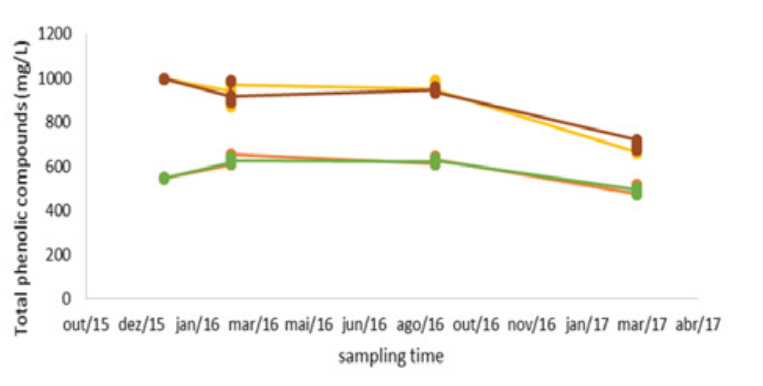

A
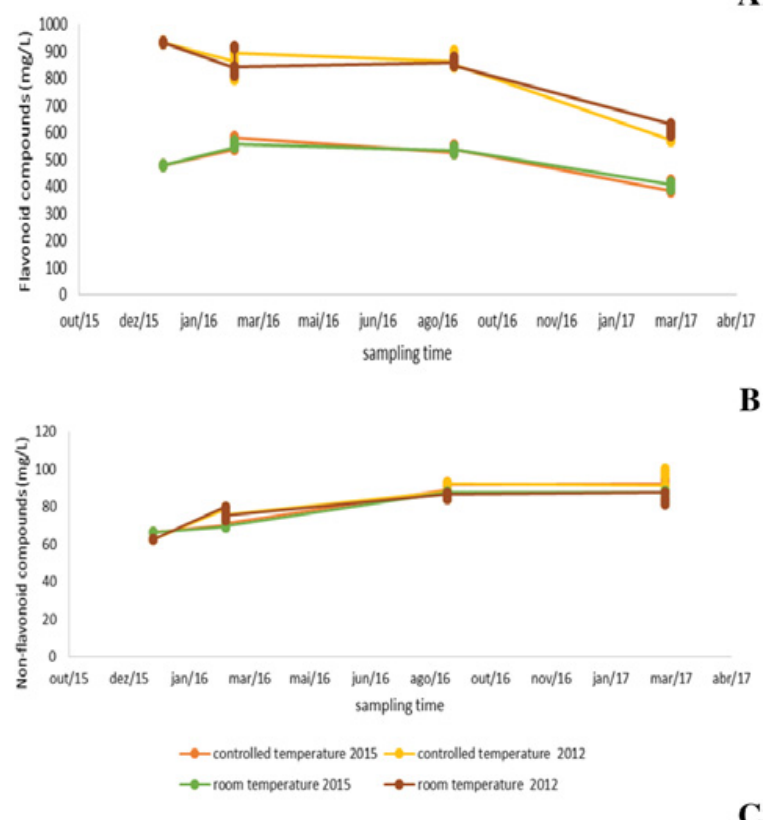

Figure 2. Total phenolic compounds (A), flavonoid phenols (B) and non-flavonoid phenols (C) of the two Tawny Port wine (vintage 2012 and vintage 2015) aged during 15 months in a winery with controlled temperature and in another at room temperature.

gallic acid to $88 \mathrm{mg} / \mathrm{L}$ gallic acid and from $62 \mathrm{mg} / \mathrm{L}$ gallic acid to $81 \mathrm{mg} / \mathrm{L}$ of gallic acid, respectively for the vintage 2015 and 2012, respectively.

\section{Conclusions}

Concerning the wine's average cumulative daily redox potential, it was the parameter that has showed higher differences between barrels positioned in the same winery, with a maximum of $40 \%$ relative standard deviation in barrels at room temperature and of $60 \%$ in barrels at a controlled temperature. Differences observed for redox potential between barrels were significantly higher than those observed for oxygen consumption.

We appreciate the financial support provided to the Research Unit in Vila Real (PEst-OE/QUI/UI0616/2014) by FCT and COMPETE and by the Agricultural and Rural Development Fund (EAFRD) and by the Portuguese government through
Measure 4.1 - Cooperation for Innovation PRODER program (Rural Development Programme), through the project INNPORT "Otimização do processo de envelhecimento do vinho do Porto Tawny". The authors would like to acknowledge Vallegre Company members, for the facilities granted in deploying the distributed monitoring system in two of their wineries and sample management.

\section{References}

[1] Portaria n. ${ }^{\circ}$ 195/85 de 10 de Abril de 1985. Diário da República n. ${ }^{\circ} 83 / 1985$ - I Série. Ministério da Agricultura. Lisboa

[2] N. Mateus, V. de Freitas, J. Agric. Food Chem. 49, 5217 (2001)

[3] M. Sánchez-Iglesias, M.L. González-Sanjosé, S. Pérez-Magariño, M. Ortega-Heras, C. GonzálezHuerta, J. Agric. Food Chem. 57, 11498 (2009)

[4] V. Carrascon, P. Fernandez-Zurbano, M. Bueno, V. Ferreira, J. Agric. Food Chem. 63, 10938 (2015)

[5] M. Day, S. Schmidt, P. Smith, E. Wilkes, Aust. J. Grape Wine Res. 21, 693 (2015)

[6] C.M. Oliveira, A.S. Barros, A.C.S. Ferreira, A.M. Silva, Food Res. Int. 75, 337 (2015)

[7] T.C. Somers, Phytochemistry, 10, 2175 (1971)

[8] E. Salas, V. Atanasova, C. Poncet-Legrand, E. Meudec, J.P. Mazauric, V. Cheynier, Anal. Chim. Acta 513, 325 (2004)

[9] J. Bakker, Vitis 25, 2031 (986)

[10] V.L. Singleton, H.W. Berg, J.F. Guymon, Am. J. Enol. Vitic. 15, 75 (1964)

[11] H.L. Wildenradt, V.L. Singleton, Am. J. Enol. Vitic. 25, 119 (1974)

[12] C.F. Timberlake, P. Bridle, Am. J. Enol. Vitic. 27, 97 (1976)

[13] T.C. Somers, M.E. Evans, J. Sci. Food Agric. 28, 279 (1977)

[14] R.J. Clarke, J. Bakker, Wine Flavor Chemistry (Blackwell Publishing, 2004)

[15] R. Morais, N. Silva, J. Mendes, T. Adão, L. Pádua, J.A. López-Riquelme, N. Pavón-Pulido, J.J. Sousa, E. Peres, Comput. Electron. Agric. 162, 882 (2019)

[16] R. Morais, E. Peres, J. Boaventura-Cunha, J. Mendes, F. Cosme, F.M. Nunes, Comput. Electron. Agric. 145, $92(2018)$

[17] OIV, International Methods of Analysis of Wines and Musts, Édicion official. Paris, Vol. 2 (2013)

[18] P. Ribéreau-Gayon, Y. Glories, A. Maujean, D. Dubourdieu, Handbook of Enology: The Chemistry of Wine Stabilization and Treatments (Wiley \& Sons Ltd. editors, 2006). Vol. 2

[19] T.E. Kramling, V.L. Singleton, Am. J. Enol. Vitic. 20, 86 (1969)

[20] I. Nevares, V. Martínez-Martínez, A. Martínez-Gil, R. Martín, V.F. Laurie, M. del Alamo Sanza, Food Chem. 635, 588 (2017)

[21] J.C. Danilewicz, Am. J. Enol. Vitic. 63, 1 (2012)

[22] P.A. Kilmartin, Chem. 73, 18 (2009) 